\title{
Cyclodextrin polyurethanes polymerised with carbon nanotubes for the removal of organic pollutants in water
}

\author{
KL Salipira, BB Mamba*, RW Krause, TJ Malefetse and SH Durbach \\ University of Johannesburg, Department of Chemical Technology, PO Box 17011, Doornfontein 2028, Johannesburg, South Africa
}

\begin{abstract}
Organic compounds are some of the major pollutants of water worldwide. They can be toxic or carcinogenic even at low concentrations. The non-reactivity of these species makes it difficult to remove them from water, particularly when present at concentration levels of nanograms per litre $\left(\mathrm{ng} \cdot \ell^{-1}\right)$ or lower. Reasonably inexpensive yet effective methods for the removal of these organic pollutants to below ppb levels are therefore required.

Insoluble cyclodextrin polyurethanes have demonstrated the ability to remove organic species from water at concentration levels of nanograms per litre. Carbon nanotubes have also been reported to efficiently adsorb some organic molecules such as dioxins and polychlorinated dibenzo-furans. However, these nanotubes are currently too expensive to be used on their own in water treatment.

An investigation into the use of cross-linked cyclodextrin polyurethanes copolymerised with functionalised multiwalled carbon nanotubes as adsorbents for organic pollutants has yielded very useful results which may have an impact in future water treatment applications.
\end{abstract}

Keywords: multiwalled carbon nanotubes, cyclodextrins, polymer composites, adsorption, trichloroethylene, endocrine disruptors

\section{Introduction}

Removal of organic compounds from water remains a big challenge for municipalities and water authorities. Such organic compounds, which include polychlorinated biphenyls (PCBs), poly-aromatic hydrocarbons (PAHs), dioxins and endocrine disrupting compounds (EDCs) can be toxic and pose serious health risks to humans and animals (Elijarrat and Barcelo, 2003). EDCs for example, have been highlighted as priority organic pollutants in the European Union Directive of 2001 (Richardson, 2004). These chemicals mimic naturally produced hormones and they interfere with the normal functions and development of organisms (Paris et al., 2006) including interrupted sexual behaviour (Richardson, 2004; Vidaeff et al., 2005). Some examples of EDCs are natural and synthetic steroid sex hormones, some polychlorinated biphenyls and dioxins.

Techniques such as the use of activated carbon, zeolites and reverse osmosis are currently being used to treat water before consumption. However, activated carbon fails to remove many organic pollutants at concentration levels of nanograms per litre (Li and Ma, 1999). Zeolites also show low affinity for organic compounds and reverse osmosis is currently too expensive for wide spread use (Li and Ma, 1999). Thus, an effective, yet economical method to remove these organic pollutants to safe concentration levels is often required.

\section{Cyclodextrin-polyurethanes containing carbon nanotubes}

Cyclodextrin based insoluble polymers have demonstrated the capacity to remove organic species in water at concentration

* To whom all correspondence should be addressed.

盄 +27 11559 6516; fax: +27 115596425 ;

e-mail: bmamba@uj.ac.za

Received 10 September 2007; accepted in revised form 14 November 2007. levels as low as $\mathrm{ng} \cdot \ell^{-1}$ ( $\mathrm{Li}$ and Ma, 1999; Mamba et al 2007). Furthermore, in our laboratories, it was found that these polymers could be recycled at least eighteen times while still maintaining high adsorption efficiency (Mhlanga et al., 2007). However, two deficits have emerged from testing these polymers with a variety of pollutants:

- They have only been demonstrated to be effective at low concentrations of organic pollutants

- Their structural integrity has been somewhat compromised after prolonged recycling.

Carbon nanotubes, though expensive to produce, have shown an ability to efficiently adsorb dioxins, polychlorinated dibenzofurans, biphenyls (Long and Yang, 2001) and some inorganic pollutants at higher concentrations. It has also been reported that multiwalled carbon nanotubes (MWNTs) can improve structural stability especially when used as polymer composites (Xu et al., 2006; Xiong et al., 2006).

Previously we have reported that cyclodextrin polyurethanes incorporated with MWNTs effectively removed $p$-nitrophenol from water with adsorption efficiency as high as $99 \%$ (Salipira et al., 2007). Herein, we further report the efficiency of these polymers to adsorb trichloroethylene, one of the priority endocrine disrupting compounds. This paper also outlines the characterisation techniques that were employed in elucidating structural identity of these novel polymers.

\section{Experimental}

Experimental techniques used in this investigation were standard and only when necessary, were modifications performed to these in order to suit the applications that were required. All chemicals that were used were of reagent grade and were purified as required. Solvents were obtained at high purity from suppliers and where necessary, they were dried and deoxygenated by distillation from sodium under argon. All reactions unless oth- 
erwise stated were performed under argon.

The structure and purity of the MWNTs were elucidated by transmission electron microscopy (using a JOEL 100S), while functional groups present before and after functionalisation were studied using FT-IR spectroscopy (MIDAC FT-IR - model 4000). Raman spectra, showing disorder and graphic nature of the nanotubes before and after functionalisation were obtained using a Jobin-Yvon T64000 Raman spectrometer.

A gas chromatograph (GC) coupled with a mass spectrometer (GC-MS) was used to analyse trichloroethylene samples. A Varian 3800 capillary GC was coupled with a Saturn 2000 ion-trap mass spectrometer (MS). The GC was equipped with a Chrompack CP Sil 8 CB, $30 \mathrm{~m} \times 0.25 \mathrm{~mm}$ capillary column with an internal diameter of $0.25 \mu \mathrm{m}$. A modified EPA method ' 8270 ' for semi-volatile organics was used for the determination and quantification of the analytes. The chromatographic conditions were $1 \mu \ell$ split-less injection at $75^{\circ} \mathrm{C}$ using helium $(\mathrm{He})$ as a carrier gas at $1.0 \mathrm{~m} \ell \cdot \mathrm{min}^{-1}$ constant gas flow. The oven temperature settings were: $30^{\circ} \mathrm{C}$ (held for $2 \mathrm{~min}$ ) to $75^{\circ} \mathrm{C}$ at $10^{\circ} \mathrm{C} \cdot \mathrm{min}^{-1}$, to $100^{\circ} \mathrm{C}$ at $20^{\circ} \mathrm{C} \cdot \mathrm{min}^{-1}$ (held for $4 \mathrm{~min}$ ). The instrument gave detection limits of below $10 \mu \mathrm{g} \cdot \ell^{-1}$. In the recycling experiments, a UV spectrometer (Cary UV 50 Scan) was used to measure adsorbance for $p$-nitrophenol at a wavelength of $318 \mathrm{~nm}$. Cuvettes (10 mm wide and $45 \mathrm{~mm}$ long) were used as sample holders.

MWNTs which were synthesised in our laboratory by reaction of toluene with ferrocene through nebulised spray pyrolysis (NSP) were used in this study. $\beta$-cyclodextrin (Cava Max W7) was supplied by Wacker Chemicals.

\section{Synthesis of carbon nanotubes}

MWNTs were synthesised using the NSP technique as reported by Vivekehand et al (2004). The basic procedure is as follows: A solution of ferrocene $(2.0 \mathrm{~g})$ in toluene $(50 \mathrm{~m} \ell)$ was nebulised by applying a high frequency $(1.5 \mathrm{MHz})$ ultrasound. This formed a spray that was carried through a quartz reactor tube by argon at a flow rate of $500 \mathrm{~m} \ell \cdot \mathrm{min}^{-1}$. The reaction temperature was maintained at $900^{\circ} \mathrm{C}$ for $45 \mathrm{~min}$ and then cooled to below $300^{\circ} \mathrm{C}$ before the nanotubes were removed. This prevented the nanotubes from being oxidised by air. The formed nanotubes were scraped from the walls of the quartz tube.

\section{Functionalisation of carbon nanotubes.}

Functionalisation by reflux in a mixture of nitric and sulphuric acids to introduce carboxylic groups to the walls of MWNTs was initially attempted by a technique developed by Esumi et al (1996). However, this technique resulted in a tremendous loss of mass in the MWNTs. Because of this limitation,

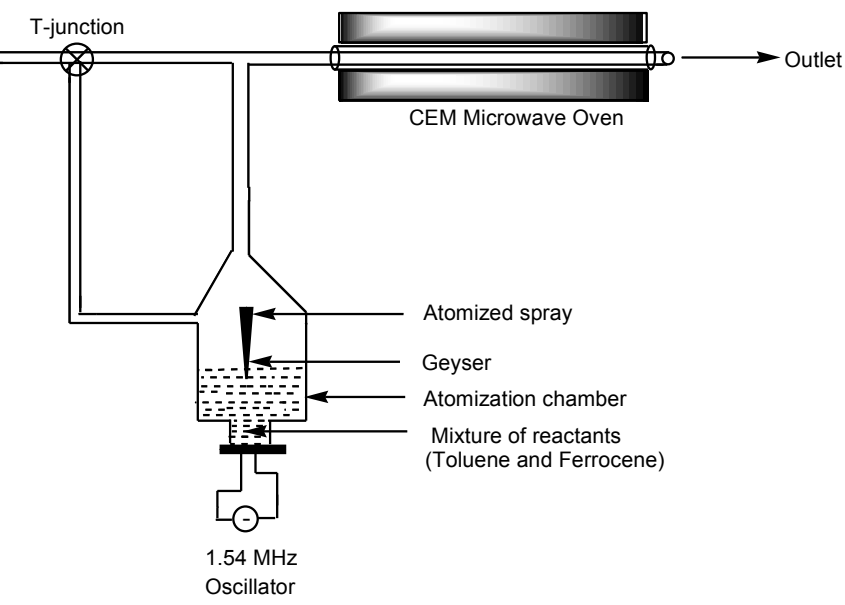

Figure 1

Schematic diagram for producing MWNTs by nebulised spray pyrolysis

a revised technique that successfully introduced the carboxylic groups, while maintaining a high yield was used and is reported below. In this technique, MWNTs $(1.00 \mathrm{~g})$ were transferred into a mixture of nitric acid $\left(10 \mathrm{~cm}^{3}\right)$ and sulphuric acid $\left(30 \mathrm{~cm}^{3}\right)$. This mixture was then heated at $50^{\circ} \mathrm{C}$ for $24 \mathrm{~h}$ after which the MWNTs were filtered off using PTFE or Nylon filter paper (pore size $0.45 \mu \mathrm{m}$ ), diameter $47 \mathrm{~mm}$. This was followed by subsequent washing with distilled water until the $\mathrm{pH}$ was almost neutral. The MWNTs were then dried under vacuum at room temperature followed by characterisation using infrared (IR) spectroscopy, Raman spectroscopy, and transmission electron microscopy (TEM).

\section{Polymerisation of cyclodextrins with carbon nanotubes}

Beta cyclodextrin ( $\beta$-CD) $(1.00 \mathrm{~g})$, was dissolved in $N, N$-dimethyl formamide (DMF) $(18 \mathrm{~m} \ell)$ with stirring. To the solution of $\beta$-CD was added functionalised carbon nanotubes $(0.01 \mathrm{~g}, 0.02$ g, $0.04 \mathrm{~g}, 0.06 \mathrm{~g}, 0.08 \mathrm{~g}$ and $0.10 \mathrm{~g})$ previously suspended in DMF ( $2 \mathrm{m \ell}$ ). These masses represented a $1 \%, 2 \%, 3 \%, 4 \%$ and $5 \%$ nanotube composition with respect to the mass of the cyclodextrin. The mixture of the cyclodextrin and carbon nanotubes was then heated to about $70^{\circ} \mathrm{C}$ followed by a drop-wise addition of the bifunctional linker, hexamethylene diisocyanate $(2 \mathrm{~m} \ell)$. This mixture was stirred at $70^{\circ} \mathrm{C}$ under argon for $24 \mathrm{~h}$. The polymer formed was precipitated and washed with acetone in order to remove the residual solvent followed by drying under vacuum at room temperature. Scheme 1 shows the assumed polymerisation process.

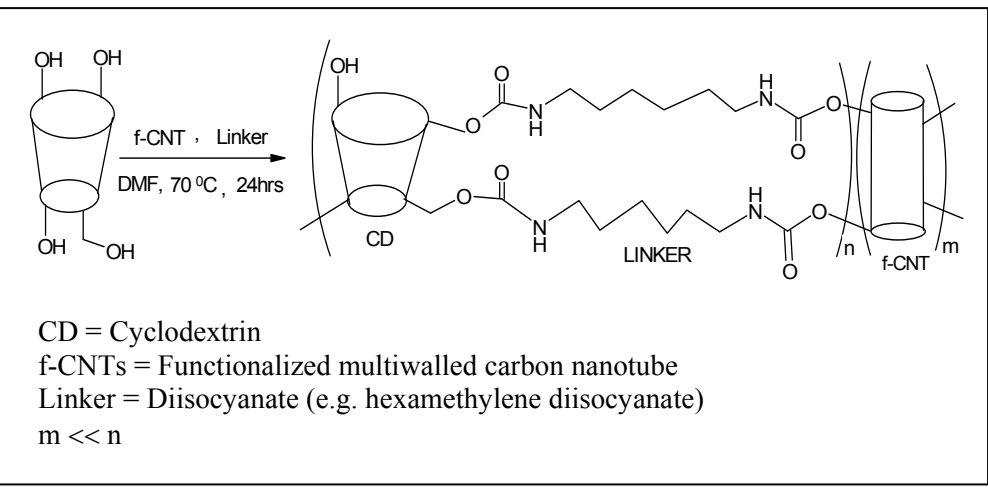

Scheme 1

Polymerisation reaction of cyclodextrin and carbon nanotubes 


\section{Analysis of trichloroethylene using gas chromatography-mass spectrometry (GC-MS)}

Water samples spiked with trichloroethylene $\left(30 \mathrm{~m} \ell, 10 \mathrm{mg} \cdot \ell^{-1}\right.$ and $\left.10 \mu \mathrm{g} \cdot \ell^{-1}\right)$ were passed through the polymers $(0.30 \mathrm{~g})$ packed in a small column $(60 \mathrm{~mm}$ long and $10 \mathrm{~mm}$ wide) at a flow rate of about $3 \mathrm{~m} \ell$ to $5 \mathrm{~m} \ell \cdot \mathrm{min}^{-1}$. The residual trichloroethylene was extracted from the eluant with dichloromethane $(15 \mathrm{~m} \ell)$ using the liquid-liquid extraction technique. This was concentrated to $1.5 \mathrm{~cm}^{3}$ and $1.0 \mu \ell$ of extract was injected into the GC-MS in order to determine the residual trichloroethylene in sample after passing through the polymer. Standard water samples (30 $\mathrm{m} \ell, 10 \mathrm{mg} \cdot \ell^{-1}$ and $\left.10 \mu \mathrm{g} \cdot \ell^{-1}\right)$ without passing through the polymer were extracted with DCM $(15 \mathrm{~m} \ell)$ and $1 \mu \ell$ was injected into the GC-MS. The instrumental technique was a modified method for the analysis of semi-volatiles for the Environmental Protection Agency (EPA) '8270'.

\section{Recycling experiments}

Recycling studies for a $1 \%$ MWNT ( $\beta-\mathrm{CD} / \mathrm{HMDI})$ polymers were performed using $p$-nitrophenol. It was chosen as a pollutant in these studies because of its characteristic yellow colour that made it easy for monitoring adsorption using UV-Visible spectroscopy. $p$-Nitrophenol $\left(30 \mathrm{~m} \ell, 10 \mathrm{mg} \cdot \ell^{-1}\right)$ was passed through the polymers $(0.30 \mathrm{~g})$. A concentration of $10 \mathrm{mg} \cdot \ell^{-1} p$-nitrophenol was used to in order to make certain that the polymer was saturated. The eluant was collected and residual $p$-nitrophenol was measured using UV-Visible spectrometer as described in the experimental section. The polymers were regenerated by passing $35 \mathrm{~m} \ell$ of ethanol (70\%) followed by washing with water $(5 \mathrm{~m} \ell)$. The process was repeated 25 times. Similarly, native $\beta$-CD/HMDI polymers were recycled in order to compare adsorption efficiency and structural stability of the 2 polymers after recycling for a particular number of times.

\section{Results and discussion}

\section{Functionalisation of carbon nanotubes}

Functionalised nanotubes were obtained in quantitative yields (76\%) These were then characterised by IR spectroscopy in order to ascertain introduction of carboxyl groups to the walls of the nanotubes through functionalisation. Figures $2 \mathrm{a}$ and $2 \mathrm{~b}$ show IR chromatograms before and after functionalisation.

It can be observed from Fig. 2a that unfunctionalised MWNTs had limited functional groups already. These were $\mathrm{O}-\mathrm{H}\left(3446 \cdot \mathrm{cm}^{-1}\right)$ and $\mathrm{C}=\mathrm{C}\left(1625 \cdot \mathrm{cm}^{-1}\right)$. After functionalising with a mixture of $\mathrm{HNO}_{3}$ and $\mathrm{H}_{2} \mathrm{SO}_{4}$, peaks corresponding to $\mathrm{O}-\mathrm{H}\left(3429 \cdot \mathrm{cm}^{-1}\right), \mathrm{C}-\mathrm{H}\left(2929 \cdot \mathrm{cm}^{-1}\right), \mathrm{C}=\mathrm{O}\left(1721 \cdot \mathrm{cm}^{-1}\right), \mathrm{C}=\mathrm{C}$ $\left(1638 \cdot \mathrm{cm}^{-1}\right)$ and C-O (1 094. $\left.\mathrm{cm}^{-1}\right)$ emerged (Fig. 2b). Comparison of the peak intensities before and after functionalisation (Figs. 2a and 2b) clearly show that intensity for the $\mathrm{O}-\mathrm{H}$ peak increased after functionalisation. It is also noted that new peaks corresponding to $\mathrm{C}-\mathrm{H}, \mathrm{C}=\mathrm{O}$, and $\mathrm{C}=\mathrm{O}$ appeared after MWNTs reacted with nitric and sulphuric acid. The increase in intensity of the $\mathrm{O}-\mathrm{H}$ peak after functionalisation and the appearance of $\mathrm{C}-\mathrm{H}, \mathrm{C}=\mathrm{O}$ and $\mathrm{C}-\mathrm{O}$ bonds suggest that oxidation of the MWNTs successfully introduced carboxyl groups $(\mathrm{COOH})$ onto the walls of the nanotubes. The $\mathrm{C}-\mathrm{H}$ signals in the IR spectrum further confirms that carbon atoms of the functionalised carbon nanotubes were now $\mathrm{sp}^{3}$ hybridised
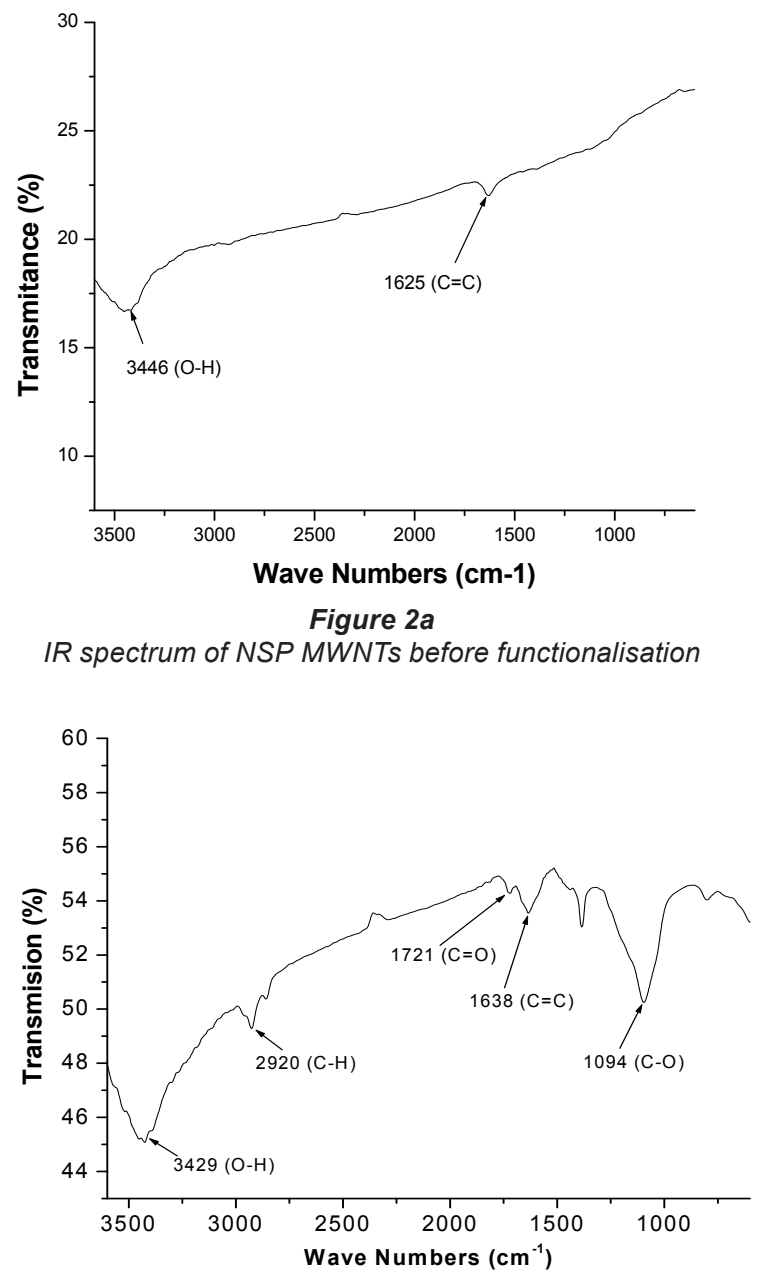

Figure $2 b$

IR spectrum of MWNTs after functionalisation

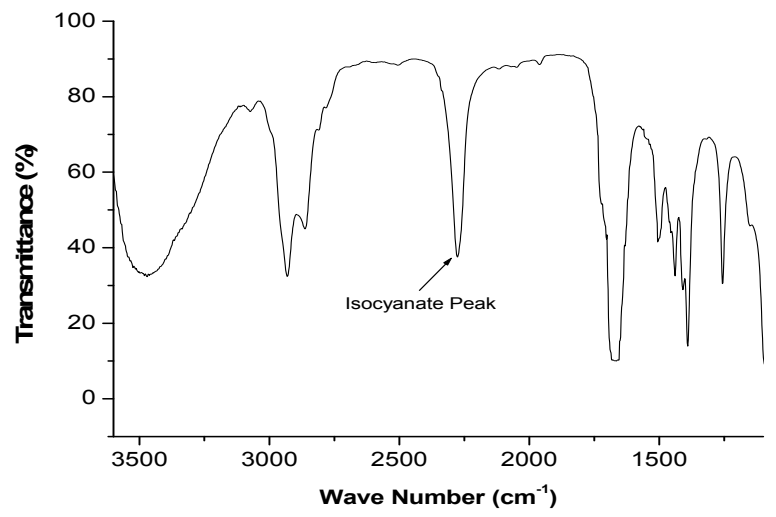

Figure 3

IR spectrum showing isocyanate peak at start of reaction

instead of being $\mathrm{sp}^{2}$ hybridised; the hybrid state of unfunctionalised carbon nanotubes.

\section{Characterisation of cyclodextrin polyurethanes containing nanotubes}

Evidence of polymerisation is the disappearance of the isocyanate peak in the IR spectrum at about $2700 \mathrm{~cm}^{-1}$. It is observed in Fig. 3 that the isocyanate peak gradually reduced 


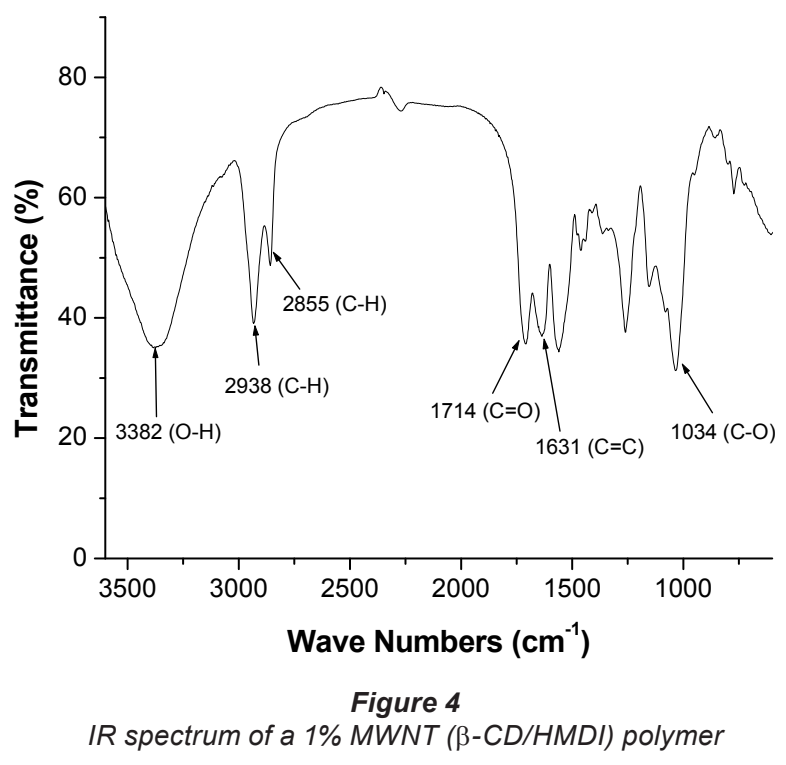

and finally disappeared after about sixteen hours of polymerisation. This was an indication that polymerisation was complete.

The synthesised polymers were obtained in quantitative yields and were insoluble in water and organic solvents. Insolubility in water was an important characteristic of the polymers in order to use them in water treatment. Characterisation of the polymers was performed using IR and scanning electron microscopy (SEM). Figure 4 shows an IR spectrum of a $1 \%$ MWNT $(\beta-\mathrm{CD} / \mathrm{HMDI})$ polymer.

The IR spectrum of the polymer show characteristic adsorption bands. These bands correspond to $\mathrm{O}-\mathrm{H}\left(3382 \cdot \mathrm{cm}^{-1}\right), \mathrm{C}-\mathrm{H}$ (2 938. $\left.\mathrm{cm}^{-1}\right), \mathrm{C}=\mathrm{O}\left(1714 \cdot \mathrm{cm}^{-1}\right), \mathrm{C}=\mathrm{C}\left(1631 \cdot \mathrm{cm}^{-1}\right)$ and $\mathrm{C}-\mathrm{O}(1$ $\left.034 \cdot \mathrm{cm}^{-1}\right)$ which further confirm that polymerisation between monomers and the linker did take place.

In order to confirm that the nanotubes had indeed polymerised with the linker, the MWNTs were reacted with hexamethylene diisocyanate in the absence of CD. The isocyanate peak disappeared after about $24 \mathrm{~h}$ and a completely new product was formed. The nanotubes were insoluble in water and IR spectrum of the polymerised nanotubes showed an enhanced $\mathrm{C}-\mathrm{H}$ and $\mathrm{C}=\mathrm{O}$ peaks. These results strongly suggest that nanotubes took part in the polymerisation with CDs and the linker.

\section{Testing polymers for their ability to remove pollutants from water}

Trichloroethylene (TCE) was used as a test pollutant. It was selected because it is a priority pollutant and is a well known endocrine disrupting chemical. Figures $5 \mathrm{a}$ and $5 \mathrm{~b}$ show results of the GC-MS analysis of a $30 \mathrm{~m} \ell\left(10 \mathrm{mg} \cdot \ell^{-1}\right)$ TCE passed through a native polymer and polymers containing MWNTs. It is observed that the polymers containing nanotubes were better at removing TCE from spiked water samples. For example, polymers containing 5\% MWNTs (Fig. 5b) removed almost all the TCE from water while the native polymers still had the residual TCE peak in the chromatogram. Taking into account the ion count of the TCE on the chromatograms before and after treating the water sample (Figs. 5a and 5b) with the polymers containing $5 \%$ MWNTs, a removal efficiency of at least $98 \%$ was achieved.

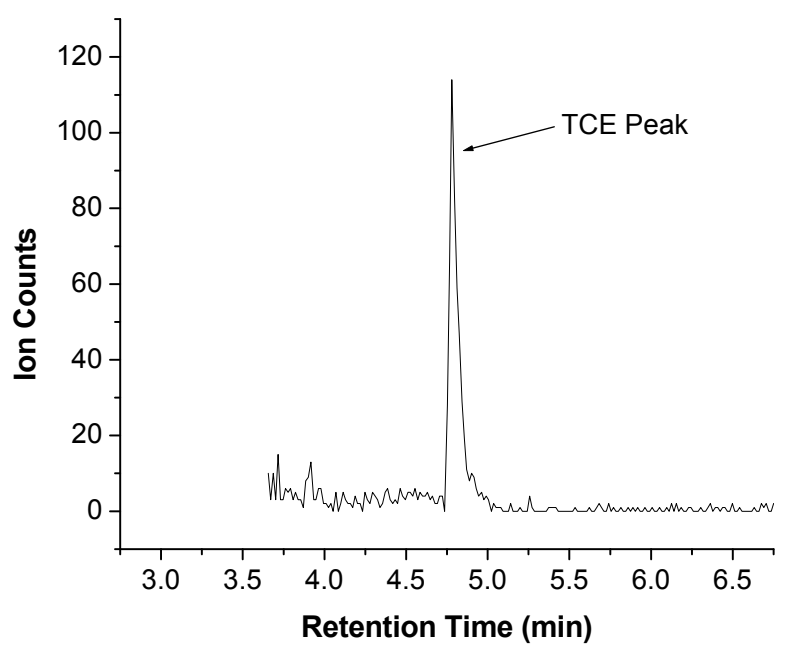

Figure 5a

GC-MS chromatogram of residual TCE after passing $30 \mathrm{ml}$ of $10 \mathrm{mg} \cdot \ell^{1}$ TCE through $0.30 \mathrm{~g}$ of $\beta-C D$ polymer

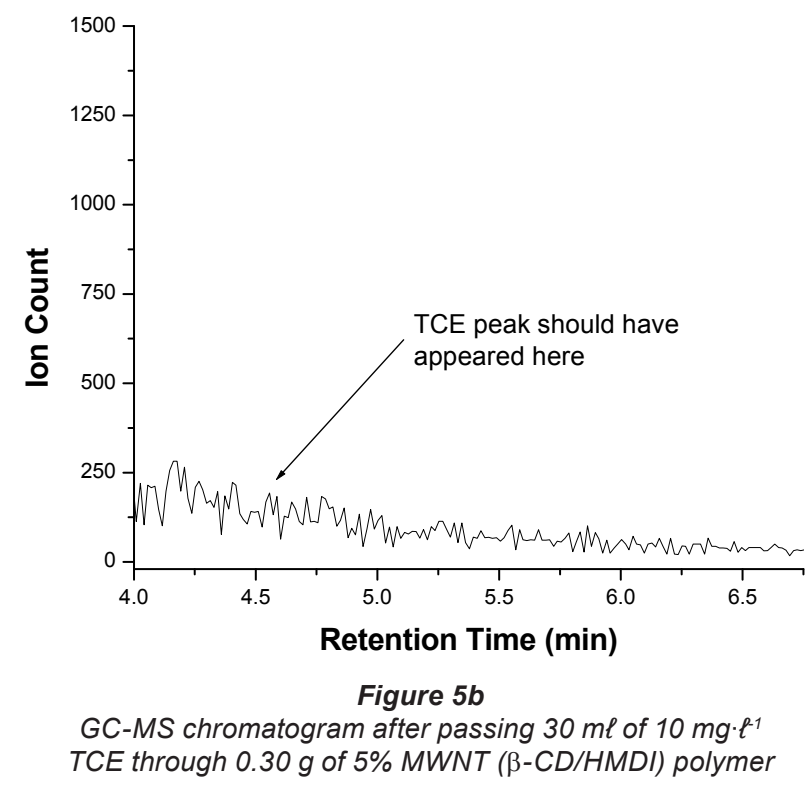

Recyclability tests of multiwalled nanotube included polymers

The ability of a polymer to be regenerated when saturation is reached is an important attribute. Such polymers are economical because the regeneration step is cheaper than the cost of replacing the polymer. In addition, such polymers are desirable because they minimise the cost convenience of replacing filter units and waste disposal of the waste. Native $\beta$-CD/HMDI polymer and a $1 \%$ MWNT $(\beta-\mathrm{CD} / \mathrm{HMDI})$ polymer were tested for their ability to be regenerated by passing $30 \mathrm{~m} \ell$ portions of a 10 $\mathrm{mg} \cdot \ell^{-1} p$-nitrophenol as the test pollutant. Results of this analysis are presented in Figs. $6 \mathrm{a}$ and $6 \mathrm{~b}$.

It is observed in Fig. $6 \mathrm{a}$ that $\beta$-CD/HMDI polymers containing nanotubes had better adsorption efficiency with an average adsorption efficiency of greater than $98 \%$ over the 25 cycles compared to the native $\beta$-CD/HMDI polymers (Fig. $6 \mathrm{~b}$ ). The polymer still maintained its spongy appearance and did not appear to have lost its structural integrity. However, the $1 \%$ MWNT ( $\beta$ - 


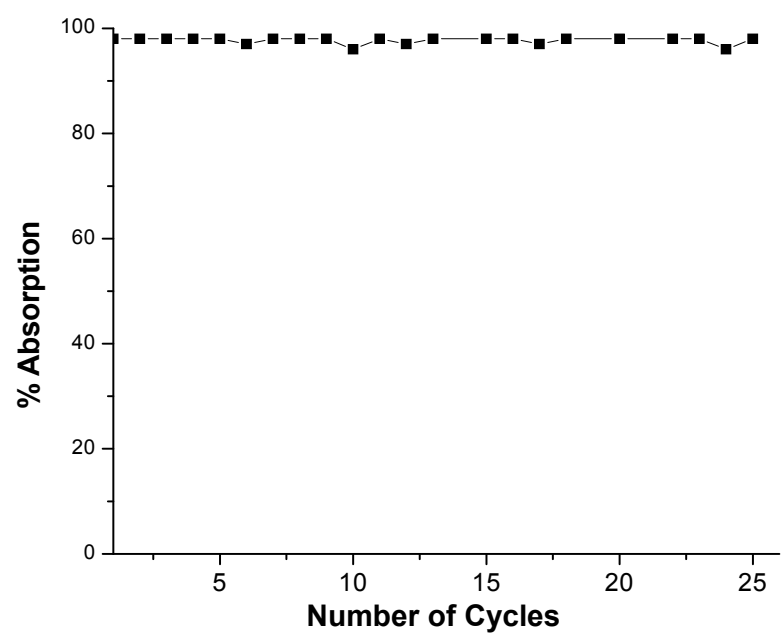

Figure 6a

Adsorption efficiencies of a recycled $1 \%$ MWNT ( $\beta-C D / H M D I)$ polymer

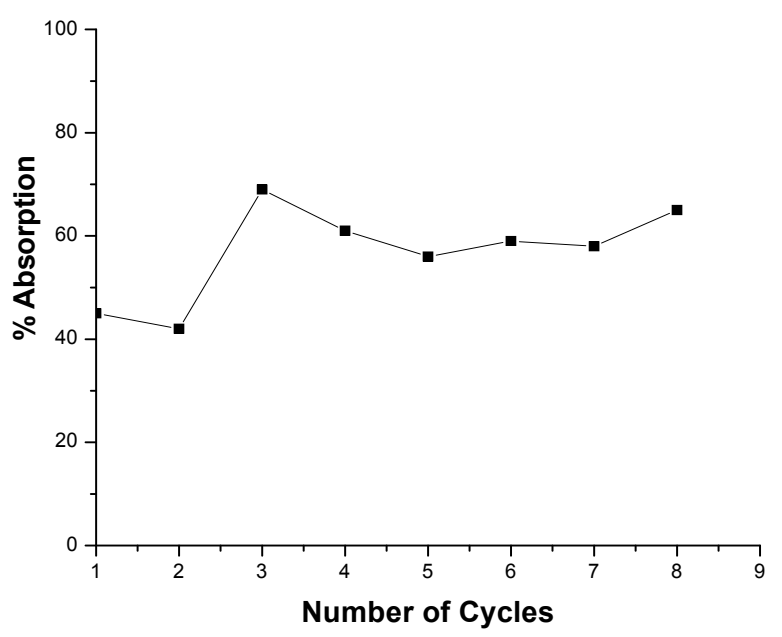

Figure $6 b$

Adsorption efficiencies of a recycled native $\beta-C D / H M D I$ polymer

CD/HMDI) polymer lost only $5 \%$ of its mass after the $9^{\text {th }}$ cycle while the native $\beta$-CD/HMDI polymer lost $17 \%$ after 9 cycles. IR spectrum (Fig. 7) shows that there was no change in adsorption peaks which further suggests that the chemical properties of the polymer were maintained.

\section{Conclusions}

It has been shown that functionalisation of the MWNTs with a mixture of $\mathrm{HNO}_{3}$ and $\mathrm{H}_{2} \mathrm{SO}_{4}$ introduced carboxylic acid and hydroxyl groups onto the nanotube walls. These groups take part in the polymerisation reaction of the nanotubes with $\beta-C D$ and the diisocyanate linkers. Furthermore, polymers containing nanotubes have shown an enhanced adsorption capacity for trichloroethylene and may offer a better solution for the removal of organic pollutants in water. These polymers, unlike granular activated carbon, can be recycled when the saturation point is reached and still maintain high adsorption efficiency while retaining the chemical properties. It has also been observed that inclusion of only $1 \%$ MWNTs into the polymer increased stability of the native polymers. This is evidenced by the mass loss

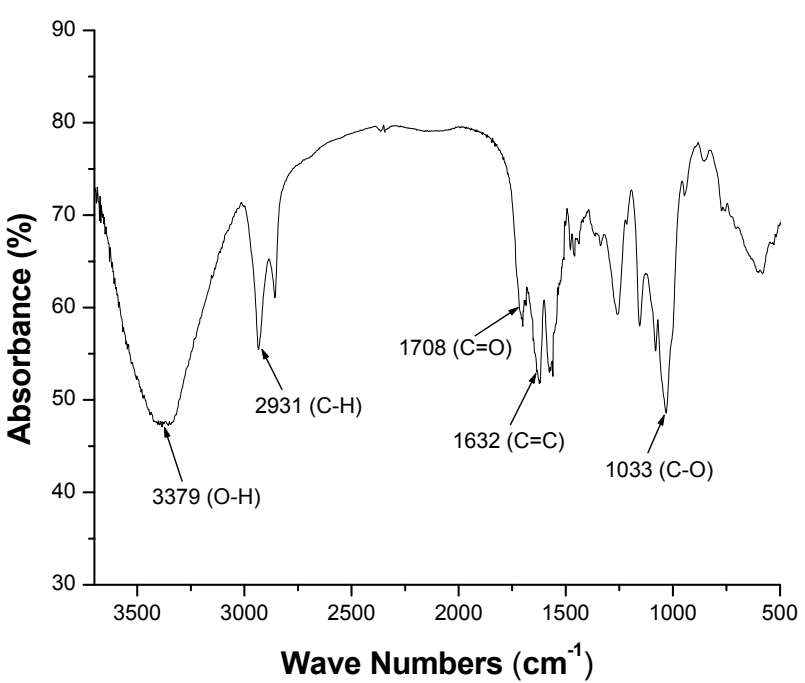

Figure 7 IR spectrum of a $1 \%$ MWNT $(\beta-C D / H M D I)$ polymer
after recycling

after recycling where $1 \%$ MWNT ( $\beta$-CD/HMDI) composite lost only $5 \%$ after 9 cycles compared to the native polymer that lost $17 \%$ after 9 cycles.

\section{Acknowledgements}

The authors wish to gratefully acknowledge funding from the National Research Foundation (NRF), Eskom's Tertiary Education Support Program (TESP), University of Johannesburg, and the Water Research Commission (WRC).

\section{References}

ELJARRAT E and BARCELO D (2003) Priority list for persistent organic pollutants and emerging contaminants. Trac. Trends in Anal. Chem. 22 655-665.

ESUMI K, ISHIGAMI M, NAKAJIMA A, SAWADA K and HONDA H (1996) Chemical treatment of carbon nanotubes. Carbon 34 279-281.

LI D Q and MA M (1999) From inclusion chemistry to water purification technology. Chemtech. 35 31-37.

LONG R and YANG R (2001) Carbon nanotubes as superior sorbent for dioxin removal. J. Am. Chem. Soc. 123 2058-2058.

MAMBA BB, KRAUSE R W, MALEFETSE TJ, MHLANGA SD, SALIPIRA KL, NXUMALO EN (2007) Removal of geosmin and 2-methylisorboneol (2-MIB) in water from Zuikerbosch Treatment Plant (Rand Water) using $\beta$-cyclodextrin polyurethanes. Water SA 33 223-227.

MHLANGA SD, MAMBA BB, KRAUSE RW, MALEFETSE TJ (2007) Removal of organic contaminants from water using nanosponge cyclodextrin polyurethanes J. Chem. Technol. Biotechnol. 82 382-388.

PARIS F, JEANDEL C and SERVANT N (2006) Increased serum estrogenic bioactivity in three male newborns with ambiguous genitalia: a potential consequence of prenatal exposure to environmental endocrine disruptors. Environ. Res. 100 39-43.

RICHARDSON DRS (2004) Environmental mass spectrometry: imaging contaminants and current issues. Anal. Chem. 76 33373362 .

SALIPIRA KL, MAMBA BB, KRAUSE RW, MALEFETSE TJ and DURBACH SH (2007) Carbon nanotubes and cyclodextrin polymers for removing organic pollutants from water. Environ. Chem. Lett. 5 13-17.

VIDAEFF AC and SEVER LE (2005) In uteral exposure to environmental estrogens and male reproductive health: a systematic review 
of biological and epidemiological evidence. Reprod. Toxicol. 20 $5-20$.

VIVEKCHAD SRC, CELE LM, DEEPACK FL, RAJU AR and GOVIN-

DARAJ A (2004) Carbon nanotubes by nebulized spray pyrolysis. Chem. Phys. Lett. 386 313-318.
XIONG J, ZHENG Z, QIN X, LI M, LI H and WANG X (2006) The thermal and mechanical properties of polyurethane-multiwalled carbon nanotube composites. Carbon 44 2701-2707.

XU M, ZANG T, GU B, WU J and CHEN Q (2006) Synthesis and properties of novel polyurethane-urea multiwalled carbon nanotube composites. Macromolecules 39 3540-3545. 